\title{
Psychometric analysis of the Tourism Wellbeing Scale (TWS): a multidisciplinary approach
}

\author{
SORAIA GARCÊS, MARGARIDA POCINHO \& SAÚL N. DE JESUS
}

\begin{abstract}
This paper analyses the Tourism Wellbeing Scale, a new measure in the tourism sector built from Positive Psychology variables: wellbeing, creativity, optimism, and spirituality. It empathizes the importance of multidisciplinary work and thus it focuses on a psychological approach to understand wellbeing in tourism. The empirical research used Exploratory Factor Analysis $(n=429)$ and Confirmatory Factor Analysis $(n=428)$. Reliability through Cronbach' Alpha was .874 and evidence of convergent validity was found with the Creative personality scale-short form, Global wellbeing scale, optimism scale, and spirituality scale. A final 8-item structure, with a one-factor solution and confirmatory analysis with: a) Normed Chi-squared ( $x 2 / \mathrm{df})=1.076$; b) Root Mean Square Residual (RMR) $=.041 ; \mathrm{c}$ ) Goodness of Fit $($ GFI $)=.992 ; \mathrm{d}$ ) Adjusted Goodness of Fit (AGFI) =.977; e) Comparative Fit Index ( $\mathrm{CFI}=.999$; and f) the Root Mean Square Error of Approximation $($ RMSEA $)=.013$ was obtained. Overall, this instrument has an adequate goodness-of-fit and acceptable psychometric quality to be used in the field. This study is an innovation in bringing a new instrument to the field based on psychological principles with the potential to help stakeholders in the development of new marketing products where wellbeing can be a major turn-point for the tourism industry.
\end{abstract}

Key words: Positive Psychology, Tourism, Tourism Wellbeing Scale, Wellbeing.

\section{INTRODUCTION}

In recent years the world has been involved in several unseen challenges like never before, including a shift in the way people think that even science could not forecast (Andreote 2018). The European Commission recognized the importance of multidisciplinary work to combat challenges in today's world, including the relevance of social sciences and humanities (Strom et al. 2018). However, it also acknowledged that "to open up for further concrete interdisciplinary approaches in European research and innovation, more efforts are needed and this is a gradual process" (Strom et al. 2018, p. 6). A dialogue between sciences is needed, looking beyond the individual fields and searching for ways where they are connected (Milanez 2015). In this study Psychology, particularly Positive Psychology joins Tourism to fill a gap in scientific research regarding the study of people that travel and, thus, joining the dialogue of interdisciplinarity.

Positive Psychology is defined by its founder as "the scientific study of the strengths, characteristics and actions that enable individuals, and communities to thrive" (Seligman 2013, p. 2). It is a science that focuses on the good things of people and what life has to offer and not only in suffering. Wellbeing, happiness, life satisfaction, optimism, and many other concepts are often linked to positive outcomes in people lives, such as more personal 
and academic success (Butler \& Kern 2016). Positive Psychology is also known as the science that studies wellbeing (Scorsolini-Comin et al. 2013) and applied to tourism it allows for new forms to interpret and understand this field.

The tourism industry is often portrayed as an economic powerhouse or a frivolous activity, but it can also be understood as an activity that aims to increase people wellbeing in a different place (Filep 2014). Tourism is mainly approached by an economic or management perspective and the social nature of who are the tourists, their values or attitudes in life are often disregarded (Simková 2014).

Tourism experiences imply changes in daily routines. It offers new places to see, and it can too increase people consciousness of their self. The host community, the accommodations, the place, the gastronomy, can all be powerful mediators of these experiences contributing to enrich people lives and bridge the need for an inner and personal reflection (Brown 2013). As Seabra et al. (2014, p. 178) regarded "tourists want to live an experience, more than simply contact with cultures, people, landscapes or places". The European Travel Commission (ETC, 2016, p.79) reported that it looks like "there is a natural bond between travel and skill-building (...) that may be because of the strong underlying link between skill-building with authenticity and meaningfulness (...) consumers today are happy to accept that understanding a foreign culture is complex; and that perhaps in order to gain the most authentic understanding of the culture they are visiting, some amount of learning may well be required". Merging Positive Psychology and Tourism can have positive results. Accordingly, to Dan (2015), this connection can lead to the development of positive mindsets increasing happiness and leading people to fully engage in their destination. It can also have a positive outcome in dealing more positively with life problems and in promoting health (Dan 2015). In a systematic literature review, Garcês et al. (2018b) studied the relationship between Positive Psychology and Tourism and found out that the number of studies is increasing. Other results from this study showed that tourism can be a promoter of wellbeing both for tourists and residents; nature is associated with wellbeing and; that wellbeing can be an important innovation opportunity for entrepreneurs.

Throughout holidays people tend to increase their physical wellbeing and overall happiness, however, when returning home these positive gains diminish very quickly (Kirillova \& Lehto 2015). This "vacation effect is thought to be triggered by the liminal nature of tourism experience as well as the ability of a tourism environment to evoke awe." (Kirillova \& Lehto 2015 p.121). Despite this reported effect researchers still, focus mainly on studying wellbeing from a hedonic perspective or subjective wellbeing theory instead of an eudaimonia approach (Kirillova \& Lehto 2015). As the ETC (2016) acknowledged there is a growing connection between self-development and a healthy lifestyle leading people to seek tourism experiences that have a meaning and a purpose. Stakeholders need to acknowledge these shifts and view them as opportunities, since these can lead to new product offers, including the idea of wellbeing as a resource for businesses.

This idea of wellbeing has been rising and it is possible to see that businesses are already combining offers in a way that leads to more meaningful experiences for tourists, while simultaneously enjoying culture and moments to relax and simply have fun. Furthermore, western societies are showing an increased interest in eudaimonic tourism experiences and new products are emerging to fulfill this gap in tourists' desires and needs (Smith \& Diekmann 2017). Research has found that people search 
for experiences that are in accordance with who they are, and this is also true when people look for a destination, selecting the one that goes along with their personalities (Passafaro et al. 2015). Plog's recognized this connection and in his model distinguished tourists' personalities according to "their internal and stable tendency to be attentive and curious about the outer world (allocentric) versus being exclusively self-centered (psychocentric), posing that people tend to choose both destinations and activities accordingly" (Passafaro et al. 2015). But researchers have also considered other theories, for example, Holland's personality types (Frew \& Shaw 1999), optimism and pessimism styles (Lee 2013) or the Big Five personality theory (Li and Tsai 2013). As Passafaro et al. (2015) acknowledged there are many ways to address the issue of tourists' preferences.

To understand wellbeing (particularly wellbeing in tourism), a multidisciplinary approach is important and as Butler \& Kern (2016, p. 1) stated: "A key element in the promotion of wellbeing is the need to measure and document levels and changes in wellbeing at the individual, community, and national levels". Some studies have developed some measures that highlight the tourism experience or associated concepts. Oh et al. (2007) developed a scale to evaluate the idea of the experience economy. Vitters $\phi$ et al. (2000) used the concept of flow to categorize tourists' experiences. Hosany and Gilbert (2010) developed the destination emotion scale, a measure focused on the emotional experiences toward a destination with three factors, namely: a) joy, b) love and c) positive surprise. Kim et al. (2012) developed the memorable tourism experience scale with psychological concepts of needs and affect, and build upon seven dimensions: a) hedonism, b) novelty, c) local culture, d) refreshment, e) meaningfulness, f) involvement and g) knowledge (Chang 2018).
More recently, Chen et al. (2018) described a multi-item scale to measure, emotional and behavioral tourist experiences at arts and cultural events. Despite the development of some instruments, to the best of our knowledge, there is not a measure that evaluates tourism wellbeing from a psychological perspective. Therefore, this study is a novelty since it brings the development and scientific validation of a new measure that aims to evaluate tourists' wellbeing from a Positive Psychology approach.

\section{MATERIALS AND METHODS}

\section{Participants}

A two-step process was used in this research: first an Exploratory Factor Analysis (EFA) and secondly a Confirmatory Factor Analysis (CFA). For the first step, a sample of 429 participants was used. Women made for $68.5 \%(n=294)$ of the sample and men for 31.2\% ( $n=134)$. Age mean (M) was 28.46 with a standard deviation (SD) of 10.83 , a minimum of 18 years old and a maximum of 73 years old. For the second step, a total of 428 subjects took part in the CFA, with $M=30.13$ years and $S D=$ of 12.827 , a minimum of 17 years old and a maximum of 76 years. Women made up for $68.9 \%$ of the sample $(n=295)$ and men $30.8 \%$ $(n=132)$.

\section{Measurements}

\section{Tourism Wellbeing Scale (TWS)}

The TWS is a self-assessment measure that aims to evaluate tourism wellbeing in each destination (Garcês et al. 2018a). It was built upon the HOPE model that states for Human Optimal Psychological Experience (Garcês et al. 2017). As the authors acknowledged the HOPE model was developed considering ideas from Positive Psychology particularly the PERMA model (Seligman 2013). HOPE encompasses a 
theoretical model where tourists' creativity, optimism, and spirituality influence their wellbeing and the activities developed in the destination also influence these variables. The interaction between them have an impact on peoples' optimal experience and is influenced by it. The TWB is composed by 30 items and eight theoretical factors regarding the following variables: a) Positive Emotions; b) Engagement; c) Relationships; d) Meaning, e) Accomplishment; f) Creativity; g) Spirituality and; h) Optimism. Responses follow a Likert scale from 1, Totally Disagree, to 7, Totally Agree. Total scores are obtained by the sum of all items ranging from a minimum of 30 to a maximum of 210 points in the 30-item form (Garcês et al. 2018a).

\section{Creative Personality Scale (CPS) - short form}

The CPS - short form (Garcês S. et al., unpublished data) was used for convergent validity analysis. CPS is a self-assessment for creative characteristics. The short form is built upon 11 items with reliability of .877 , explained variance of $44.44 \%$ and with the following goodness-offit indices: Normed Chi-squared $\left(x^{2} / d f\right)=1.38$, $p=.07$; Root Mean Square Residual (RMR) =.02; $\mathrm{GFI}=.98$; Adjusted Goodness of Fit $(\mathrm{AGFI})=.96$; Comparative Fit Index $(\mathrm{CFI})=.99$; and Root Mean Square Error of Approximation (RMSEA) $=.03$. Total scores are obtained throughout the sum of all items of the 5-points Likert scale since this is a one-factor instrument (Garcês S. et al., unpublished data).

\section{Global Wellbeing Scale (GWS)}

The GWS (Antunes R., unpublished data) is a 9-item, one-factor, self-assessment scale that evaluates wellbeing considering the PERMA Model, from Positive Psychology, as its background theory. Responses are given by a 5-point Likert scale that ranges from totally disagree (1) to totally agree (5). Total scores are obtained by the sum of all items ranging from 9 to 45 points. Results from 9 to 33 points mean low wellbeing, from 34 to 40 a medium level and from 41 to 45 means high wellbeing. Its global Cronbach alpha reported value is .808 (Antunes R., unpublished data). This measure was used for convergent validity purposes.

\section{Optimism Scale (OS)}

The OS (Barros 1998) is a 4-item scale, with only one factor and a self- assessment measure of optimism, used in this study to evaluate convergent validity. Responses occur through a Likert scale from 1 (totally disagree), 2 (disagree), 3 (neither), 4 (agree) and 5 (totally agree). Scores vary from 4 to 20 points by the sum of all items. Global Cronbach alpha for the original study was .75 .

\section{Spirituality Scale (SS)}

The SS (Pinto \& Pais-Ribeiro 2007, 2010) is a 5-item measure that aims to evaluate spirituality with items focused on the meaning of life/beliefs (built by the mean of the items 1 and 2) and positive life perspective and hope (build through the mean of items 3, 4 and 5). Responses are given by a Likert scale from 1 (Do not agree), 2 (somewhat agree), 3 (mostly agree) and 4 (Completely agree). Internal consistency of Pinto \& Pais-Ribeiro (2007) study showed the reliability of .92 for the beliefs factor, .69 for hope/optimism and for the global scale value of .74. This measure was also used in this study for convergent validity analysis.

\section{Procedures for data collection and statistical analysis}

Data were collected in two ways: online through social media sharing and by paper within social groups (by convenience) always having confidentiality and data privacy clearly explained. 
Statistical analysis involved first an exploratory factor analysis (EFA) to explore the structure of the scale, with no rotation and considering Kaiser criterion and factorial weights above .3. Results for the Kaiser-MeyerOlkin (KMO) test were also acknowledged and a cut-off of .60 considered as the most desirable, according to literature (Pestana \& Gajeiro 2008). A second and a third step involved again an exploratory analysis to find an adequate scale structure. Fourthly, a convergent validity analysis was performed using Pearson correlation. The second step consisted of a confirmatory factor analysis (CFA) considering the following indices and cut-offs: a) Normed Chi-squared $\left(x^{2} / d f\right)<$ 2 with a non-significant $p$-value; b) Root Mean Square Residual $(R M R) \leq .05 ; c)$ Goodness of Fit $(\mathrm{GFI})>.90 ;$ d) Adjusted Goodness of Fit $(\mathrm{AGFI})>$ .90; e) Comparative Fit Index $(\mathrm{CFI})>.90$; and f) the Root Mean Square Error of Approximation (RMSEA) $\leq .05$. Modification indices (MI) were also applied to improve model fit.

\section{RESULTS}

\section{Exploratory Factor Analysis and Reliability}

Analysis of the Kaiser criterion showed a fourfactor solution, the first one explaining $53.44 \%$ of the variance, the second $5.96 \%$, the third $4.74 \%$ and the fourth $3.77 \%$. The visualization of the scree plot, however, showed evidence for a onefactor structure (Figure 1).

After, observing the variance of the four factors and the scree plot a second analysis was performed, this time forced to one-factor, with varimax rotation and factorial weights above .3. KMO was .96 and the explained variance of one factor was $53.44 \%$. All factorial weights were above .5 for this one-factor solution. Cronbach' Alpha for the 30 items was .968 .

The next step to reduce the scale from 30 to 8 items was an in-depth qualitative analysis of each item and its factorial weight since it was deemed important to ensure that each one was adequate to the overall aim of this instrument to evaluate tourism wellbeing. Likewise, it

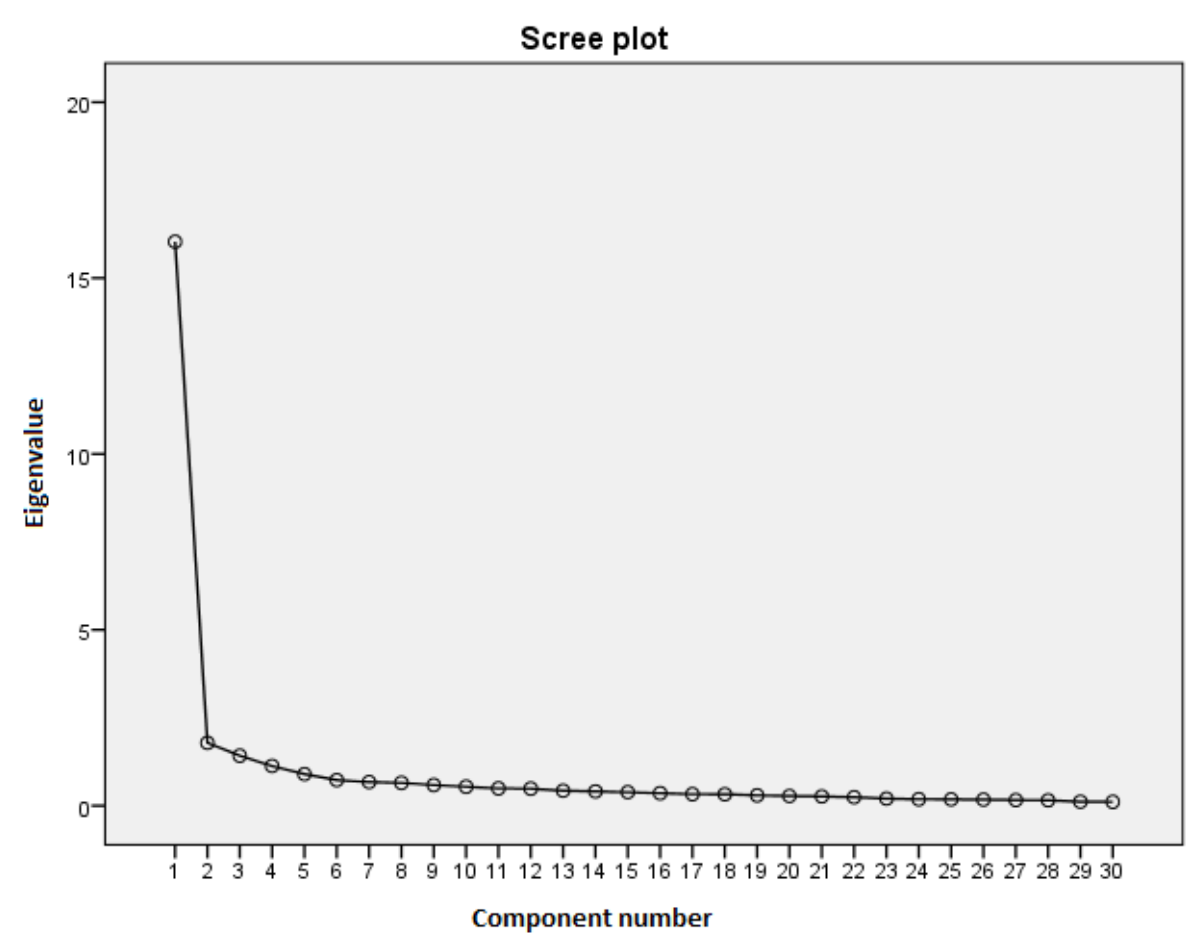

Figure 1. Scree Plot for the original 30 items. 
was also considered fundamental to have a short measure to avoid social desirability and boredom from participants. Thus, two expert researchers conducted a qualitative analysis of these statistical results, while simultaneously considering the eight theoretical factors (optimism, meaning, positive emotions, creativity, engagement, accomplishment, spirituality and positive relationships) that were the starting point of the development of the original 30-item scale (Garcês et al. 2018a). Therefore, to clarify, in the 30 -item scale, 1) optimism was built by the items 3, 6 and 24; 2) meaning by the items 8, 17 and 26 ; 3) positive emotions by the items 10, 20, 23 and 29 ; 4) creativity was composed by the items $1,11,16$ and 25; 5) engagement by items 13 and 28; 6) accomplishment by the items 5, 14, 21 and 30; 7) spirituality was composed by items 2, 7, 12, 15 and 19; and finally 8) positive relationships was built by items 4, 9, 18, 22 and 27 (Table I) (Garcês et al. 2018a). From each of these theoretical factors, one item was chosen according to the highest factorial weight and, simultaneously, considering the item that better described the factor itself according to the original definitions. Thus, after analyzing the original definitions (Garcês et al. 2018a) and the items factorial weights, each expert selected an item for each factor. After this initial selection, both experts compare their results and when a disagreement occurred, a discussion took place until an agreement between both was settled. Therefore, both experts had to agree on the selected items that had better psychometric adequacy but at the same time, better described the underlying factor. Finally, eight items were selected, one for each factor (Table I). The selected eight items were submitted to an EFA to analyze the structure of this reduced form. Principal component analysis, with no rotation and factorial weights above .30 , were performed. KMO showed a value of .90. Kaiser criterion retained only one factor with an explained variance of 53.96\%. The scree plot showed that the retention of one factor is appropriate (Figure 2).

All factorial weights were above .60 as can be seen in Table I. The eight items structure was

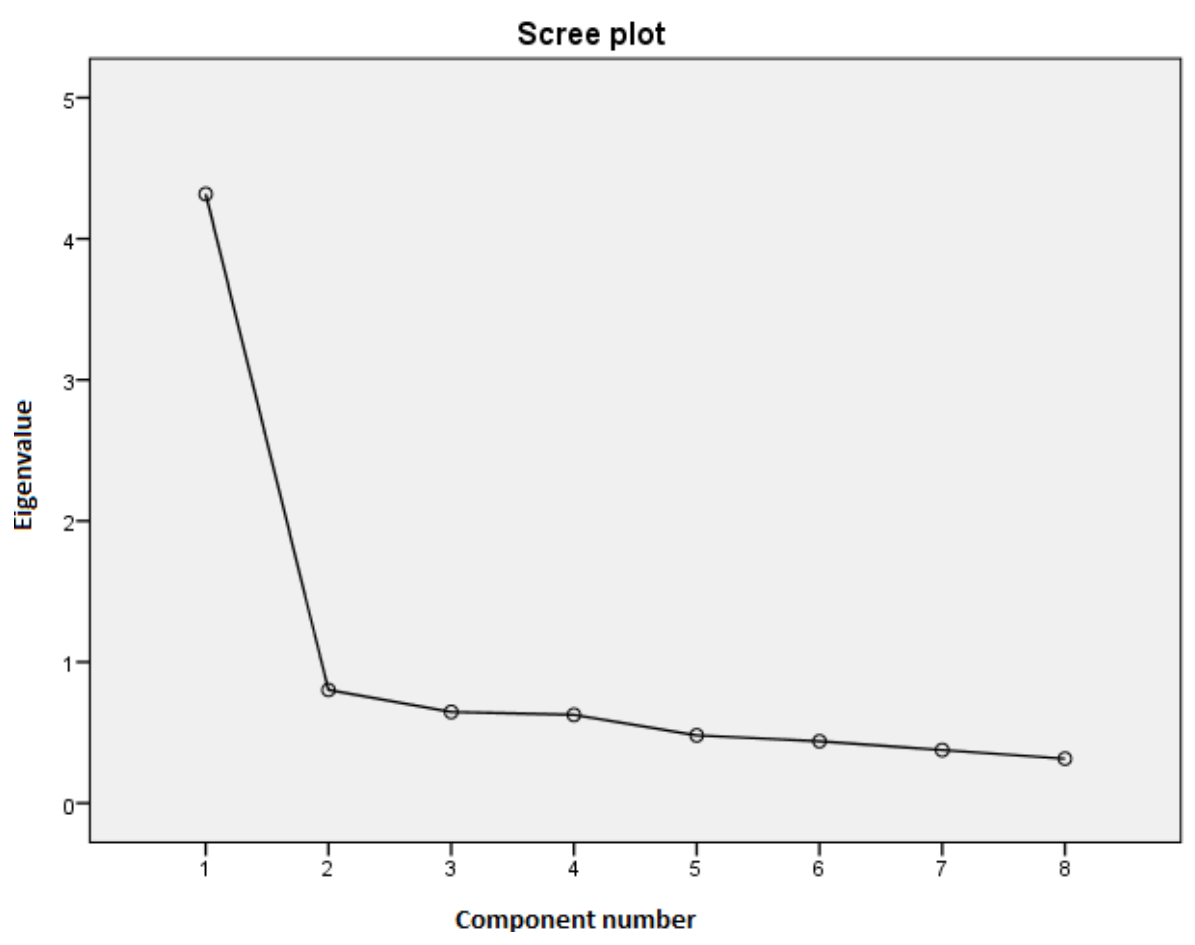

Figure 2. Scree Plot for the 8 items of the TwS. 
Table I. Factorial weights for the eight items.

\begin{tabular}{|c|c|c|c|}
\hline Factor & 30-item scale & 8-item scale & $\begin{array}{l}\text { Factorial } \\
\text { Weight }\end{array}$ \\
\hline 1.Optimism & 3,6 and 24 & $\begin{array}{l}\text { 6. I was able to see the positive side of the less agreeable } \\
\text { situations that occurred. }\end{array}$ & .74 \\
\hline 2.Meaning & 8,17 and 26 & $\begin{array}{l}\text { 8. I found out new ways of being that gave meaning to } \\
\text { aspects of my life }\end{array}$ & .78 \\
\hline 3.Positive Emotions & 10, 20, 23 and 29 & 10. I had lots of fun. & .69 \\
\hline 4.Creativity & 1, 11, 16 and 25 & $\begin{array}{l}\text { 11. I faced this experience as a unique / original } \\
\text { opportunity. }\end{array}$ & .79 \\
\hline 5.Engagement & 13 and 28 & $\begin{array}{l}\text { 13. I engaged in the community activities (ex. cultural, } \\
\text { events, etc.) }\end{array}$ & .67 \\
\hline 6.Accomplishment & $5, \mathbf{1 4}, 21$ and 30 & 14. This experience was a dream come true. & .74 \\
\hline 7.Spirituality & $2,7,12,15$ and 19 & $\begin{array}{l}\text { 19. I experienced a connection/relationship with } \\
\text { something higher than myself }\end{array}$ & .70 \\
\hline $\begin{array}{l}\text { 8.Positive } \\
\text { Relationships }\end{array}$ & 4, 9, 18, 22 and 27 & $\begin{array}{l}\text { 27. I felt good in the relationship I developed with new } \\
\text { people. }\end{array}$ & .75 \\
\hline
\end{tabular}

analyzed for reliability through Cronbach' Alpha achieving a value of .874. No item elimination was needed since it would not improve reliability. The item-total correlation was above .50 for all items.

\section{Convergent validity evidence}

Convergent validity was observed with measures for creativity, optimism, spirituality, and wellbeing. Table II shows the correlation results between all measures and the eight-item scale.

Almost all variables correlated significantly. For convergent validity the following correlations are highlighted: a) the correlation between item 6 (optimism) and the optimism measure was .234 $(p<.01)$; b) the correlation between item 8 (meaning) and the wellbeing scale was $.293(p<.01)$ and between item 8 (meaning) and 'hope' was .250 ( $p<.01)$; c) the correlation between item 10 (Positive emotions) and the wellbeing measure was .361 $(p<.01)$; d) the correlation between item 11 (creativity) and the creativity measure was $.234(p<.01)$; e) the correlation between item 13 (engagement) and the wellbeing measure was .273 $(p<.01)$; $f)$ the correlation between item 14 (accomplishment) and the wellbeing measure was .261 $(p<.01) ; g)$ the correlation between item 19 (spirituality) and the wellbeing measure was .324 $(p<.01)$ and between item 19 and the spirituality measure was $.194(p<.01)$ for 'beliefs' and .267 ( $p<.01)$ for 'hope'; and h) the correlation between item 27 (positive relationships) and the wellbeing measure was $.295(p<.01)$. The displayed results showed evidence for convergent validity for the TWS.

\section{Model fit}

A CFA for the model of one-factor composed of eight items was conducted with two models. The first one without the addition of modification indices (MI) and the second one with it. As can be seen in Table III the results for the first model were not the best ones. Thus, to improve the model, modification indices were introduced. Again, as can be seen in Table III, after the MI, model 2 presented adequate values of fit. Figure 3 shows the final structure of the instrument. 


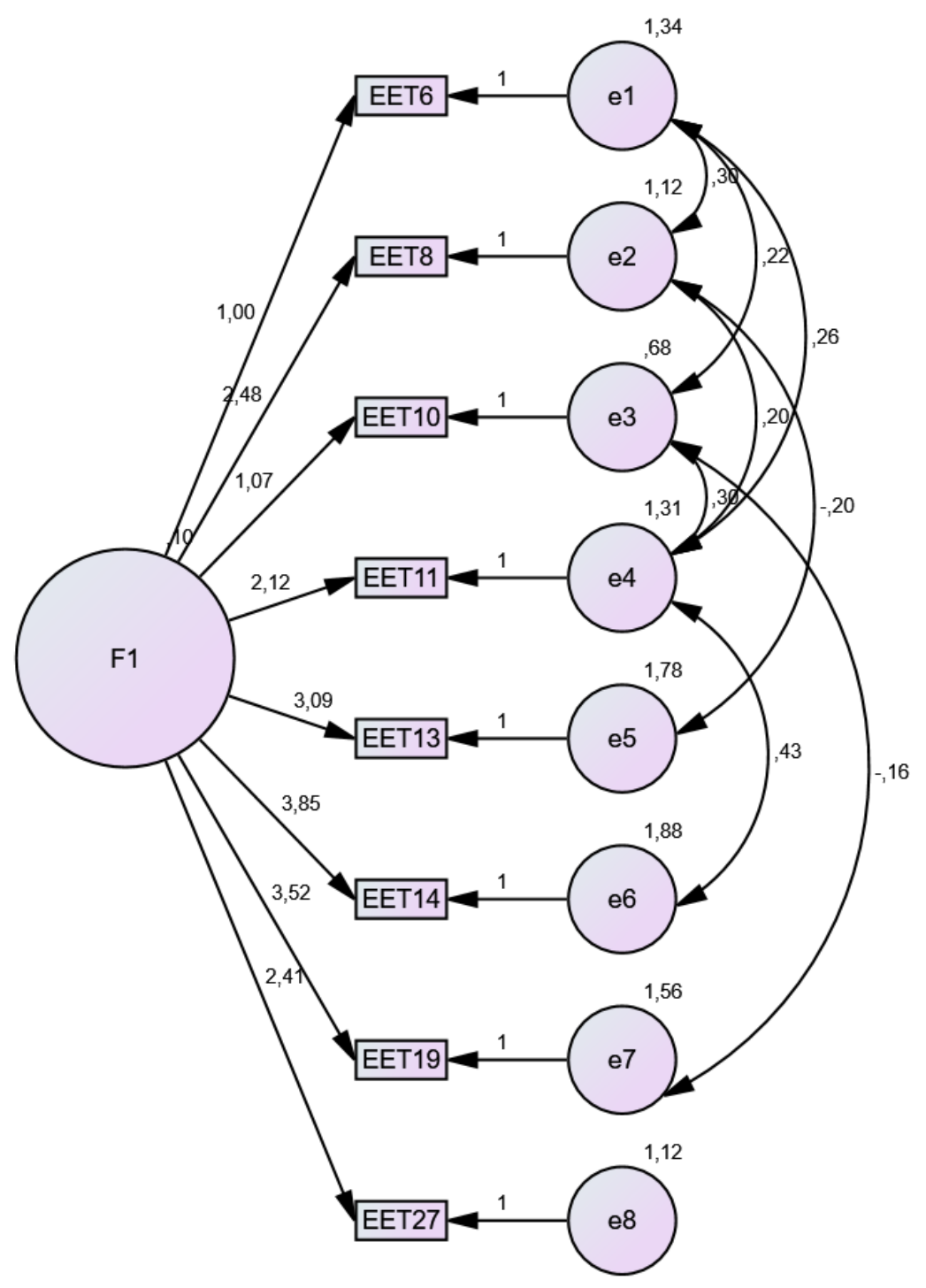

Figure 3. Model 2 for the TWS Short Form Structure.

\section{Scoring and interpretation}

The TWS is analyzed through the sum of the eight items, ranging from 8 to 56 points. Combining the two participants samples, for this study, the global mean $(M)$ for all valid cases was 40.86 with a Standard Deviation (SD) of 8.15, a minimum result of 14 , and a maximum of 56 was achieved. Asymmetry statistics was -.526, with a standard error of .085. Curtose statistics was .118, with a standard error of .170 .

For interpretation purposes, percentiles 33 and 66 were used considering the total distribution. Results show $\mathrm{P}(33)=38$ and $\mathrm{P}(66)=$ 45 , thus low wellbeing score ranges from 8 to 38 points; average wellbeing from 39 to 44 points and high wellbeing from 45 to 56 points.

\section{DISCUSSION}

A multidisciplinary view of the world and of how to solve problems and find solutions is a must to face today's challenges. The importance of introducing social sciences in scientific and "real-world" endeavors is rising 
Table II. Pearson correlation for convergent validity.

\begin{tabular}{|c|c|c|c|c|c|c|c|c|c|c|c|c|c|}
\hline & $\begin{array}{l}\text { Item } \\
6\end{array}$ & $\begin{array}{l}\text { Item } \\
8\end{array}$ & $\begin{array}{c}\text { Item } \\
10\end{array}$ & $\begin{array}{c}\text { Item } \\
11\end{array}$ & $\begin{array}{c}\text { Item } \\
13\end{array}$ & $\begin{array}{c}\text { Item } \\
14\end{array}$ & $\begin{array}{c}\text { Item } \\
19\end{array}$ & $\begin{array}{c}\text { Item } \\
27\end{array}$ & CPS & GWS & OS & $\begin{array}{c}\text { SS- } \\
\text { Beliefs }\end{array}$ & $\begin{array}{l}\text { SS- } \\
\text { Hope }\end{array}$ \\
\hline Item 6 & 1 & $.574^{\star \star}$ & $.466^{* *}$ & $-532^{* *}$ & $.410^{* *}$ & $.395^{* *}$ & $.422^{\star \star}$ & $.508^{\star *}$ & $.272^{\star *}$ & $.262^{\star *}$ & $.234^{* *}$ & .067 & $.252^{\star *}$ \\
\hline Item 8 & & 1 & $.399^{* *}$ & $.536^{\star *}$ & $.438^{* *}$ & $.521^{\star *}$ & $.528^{* *}$ & $.552^{\star *}$ & $.252^{\star *}$ & $.293^{* *}$ & $.216^{\star *}$ & .076 & .250 ** \\
\hline $\begin{array}{c}\text { Item } \\
10\end{array}$ & & & 1 & $.629^{\star *}$ & $.400^{* *}$ & $.426^{\star *}$ & $.316^{\star *}$ & $.444^{\star *}$ & $.234^{\star *}$ & $.361^{* *}$ & $.235^{\star *}$ & .069 & $.262^{* *}$ \\
\hline Item 11 & & & & 1 & $.421^{\star *}$ & $.579^{\star *}$ & $.427^{\star *}$ & $.474^{\star *}$ & $.234^{* *}$ & $.272^{\star \star}$ & $.202^{\star *}$ & .030 & $.239^{* *}$ \\
\hline Item 13 & & & & & 1 & $.415^{\star \star}$ & $.436^{\star \star}$ & $.476^{\star *}$ & $.295^{\star *}$ & $.273^{* *}$ & $.252^{\star \star}$ & .038 & $.148^{\star *}$ \\
\hline $\begin{array}{c}\text { Item } \\
14\end{array}$ & & & & & & 1 & $.514^{\star *}$ & $.469^{\star *}$ & $.250^{\star \star}$ & $.261^{* *}$ & $.186^{* *}$ & $.117^{*}$ & $.221^{\star *}$ \\
\hline $\begin{array}{c}\text { Item } \\
19\end{array}$ & & & & & & & 1 & $.483^{\star \star}$ & $.247^{\star *}$ & $.324^{* *}$ & $.261^{* *}$ & $.194^{* *}$ & $.267^{* *}$ \\
\hline Item 27 & & & & & & & & 1 & $.251^{\star \star}$ & $.295^{* *}$ & $.215^{\star \star}$ & .077 & $.178^{\star *}$ \\
\hline CPS & & & & & & & & & 1 & $.583^{\star \star}$ & $.494^{\star *}$ & $.203^{* *}$ & $.378^{\star *}$ \\
\hline GWS & & & & & & & & & & 1 & $.637^{\star *}$ & $.355^{\star *}$ & $.621^{\star *}$ \\
\hline OS & & & & & & & & & & & 1 & $.211^{\star \star}$ & $.599 * *$ \\
\hline $\begin{array}{c}\text { SS - } \\
\text { Beliefs }\end{array}$ & & & & & & & & & & & & 1 & $.426^{\star *}$ \\
\hline $\begin{array}{c}\text { SS } \\
\text {-Hope }\end{array}$ & & & & & & & & & & & & & 1 \\
\hline
\end{tabular}

Note. ${ }^{* *} p<.01 ;{ }^{*} p<.05 ;$ Item 6 = optimism; Item 8 = Meaning; Item 10 =Positive Emotions; Item 11 = Creativity; Item 13 = Engagement; Item 14 = Accomplishment; Item 19 = spirituality; Item 27 = Positive relationships; CPS = Creative Personality Scale; GWS = Global Wellbeing Scale; OS = Optimism scale; SS - Beliefs = Spirituality Scale Beliefs factor; SS - Hope = Spirituality Scale Hope factor.

Table III. Measures of fit for CFA.

\begin{tabular}{|c|c|c|c|c|c|c|}
\hline Model & $\mathbf{X}^{\mathbf{2} / \mathbf{d f}}$ & RMR & GFI & AGFI & CFI & RMSEA \\
\hline 1 & 5.872 & .108 & .934 & .880 & .877 & .107 \\
\hline 2 & 1.076 & .041 & .992 & .977 & .999 & .013 \\
\hline
\end{tabular}

Note. Normed Chi-squared $\left(\mathrm{X}^{2} / \mathrm{df}\right)<2$ with a non-significant $p$-value; b) RMR $\left.\leq .05 ; \mathrm{c}\right) \mathrm{GFI}>.90$; d) AGFI > .90; e) CFI > .90; and f) the RMSEA $\leq .05$

as never before and even being recognized by the European Commission as a field of great importance (Strom et al. 2018). This paper brought Psychology and Tourism together allowing to show that this complementary work between far distant fields is possible and from this interdisciplinary work new and innovative ideas can emerge. The instrument analyzed in this paper is physical evidence that this work is, not only possible but achievable. In the overall picture of the tourism system, the Tourism Wellbeing Scale presents itself as a need since, to the best of the authors' knowledge, there is not a measure that encompasses wellbeing with principles from Positive Psychology and simultaneously evaluates wellbeing in a given tourism destination. The world is seeing changes in how people think (Andreote 2018) and behave with impact on their needs and desires and wellbeing is getting each day more attention. 
Positive Psychology as the science that studies it (Scorsolini-Comin et al. 2013) can make a major difference in its understanding and, thus, it is a natural ally to the study of wellbeing in tourism. The results from this paper show that the Tourism Wellbeing Scale is an adequate psychometric instrument showing great potential to explore psychological wellbeing in tourism destinations. Thus, it is a measure that can be used to better understand who the tourist is, from a psychological viewpoint and, therefore fill a gap that is often forgotten or disregarded, namely to understand the tourist as a person (Simková 2014). It is also an instrument that, by allowing to evaluate tourists' wellbeing it, can give insights to the advance of new and better strategies to increase and promote wellbeing in a destination, including the development of new marketing products. As Smith \& Diekmann (2017) regarded wellbeing is already recognized as an innovation for businesses, but still more needs to be done. Therefore, this new instrument can be of great use to not only researchers but also stakeholdersin the tourism industry. Overall, from the statistical analysis of this scale, the decrease of the number of items from 30 to 8 appears to be an adequate step since it is well known that long questionnaires are many times disregarded by participants or that social desirability is not a welcoming occurrence when analyzing data. This reduction seems also adequate since when comparing variance and reliability of the longer and shorter versions, values maintain similar results, which can lead us to think that the decrease did not affect the consistency of the instrument. The inter-correlation of items also demonstrated that the items are strong-built and have some association which was highly expected since we are evaluating an overall construct, wellbeing, through some of its main components according to a Positive Psychology perspective. Convergent validity results also go with this idea and the reported results showed that the items have a strong correlation with the measures that evaluate the variables that they aim to analyze, showing evidence of this validity. Further confirmatory analysis allowed to have more confidence in the structure of the Tourism wellbeing scale showing too adequate values.

This measure can, therefore, be of great use not only for researchers but also to help stakeholders. By giving a psychological profile of the tourist this scale can give valuable information of who is the tourist and their wellbeing and, thus, assist stakeholders to (re) design new activities or new marketing strategies to attract people to a destination.

Despite these results, the work for this new measure does not end here, more field studies are needed to see how this measure 'behaves'. One of the limitations of this study was the use of only self-assessment measures to analyze convergent validity. It is important to expand the data collection to different countries and cultures and it is also important to look for discriminant validity and convergent validity and perhaps introduce other instruments besides self-assessment instruments. Likewise, it was not possible to compare results with similar measures since, as said before, to the best of the authors' knowledge, none could be found.

Concluding, the work here presented brings a clear innovation by combining two fields that despite being quite different, theoretically, have a common ground and therefore, high probabilities of working together and creatively achieve new ideas. Interdisciplinarity is a must today. Similarly, the study of wellbeing is being regarded as fundamental to improve peoples' lives. Being tourism an activity seeks to increase wellbeing, it seems rather logical that Psychology can be an allied field to tourism. However, to study it, instruments with scientific validity are 
needed. Therefore, the Tourism Wellbeing Scale can be a measure to fill this gap.

\section{Acknowledgments}

Special thanks to ARDITI - Agência Regional para o Desenvolvimento da Investigação Tecnologia e Inovação through the support provided under the Project M142009-5369-FSE-000001 - Post Doctoral Research Grant.

\section{REFERENCES}

ANDREOTE F. 2018. How to live and do science in a changing world. An Acad Bras Cienc 90: 1-2.

BARROS J. 1998. Optimismo: Teoria e Avaliação (Proposta de uma nova escala). Psicologia, Educação e Cultura 2(2): 295- 308 .

BROWN L. 2013. Tourism: A Catalyst for Existential Authenticity. Ann Tourism Res 40: 176-190.

BUTLER J \& KERN M. 2016. The PERMA-Profiler: A brief multidimensional measure of flourishing. Int J Wellbeing 6(3): 1-48.

CHANG S. 2018. Experience economy in hospitality and tourism: Gain and loss values for service and experience. Tour Manag 64: 56-63.

CHEN Y, KING B \& LEE H. 2018. Experiencing the destination brand: Behavioral intentions of arts festival tourists, J Destin Mark Manage 10: 61-67.

DAN C. 2015. Positive Psychology in Tourism. In: Advances In Social Science, Education And Humanities Research, 49, Changsha. Proceedings of the $3^{\text {rd }}$ International Conference on Education, Management, Arts, Economics and Social Science, Changsha: Q. Dong and M. Guo, Changsha, p. 927-930.

EUROPEAN TRAVEL COMMISSION. 2016. Lifestyle trends \& Tourism: How changing consumer behavior impacts travel to Europe, Brussels: European Travel Commission, $79 \mathrm{p.}$

FILEP S. 2014. Consider Prescribing Tourism. J Travel Med 21(3): 150-152.

FREW E \& SHAW R. 1999. The relationship between personality gender and tourism behavior. Tour Manag 20: 193-202.

GARCÊS S, POCINHO M \& JESUS S. 2017. Positive Psychology Research as a Framework for a new conceptual model in Tourism Settings. In: Milcu M and Dahl I (Eds), Modern Research in Health, Education and Social Sciences.
From Evaluation to Intervention, Bucaresti: Editura Universitarã, Romania, p. 339-344.

GARCÊS S, POCINHO M \& JESUS S. 2018a. Development of the Tourism Wellbeing Scale. Revista de Divulgação Científica-AICA 10: 55-63.

GARCÊS S, POCINHO M, JESUS S \& RIEBER M. 2018b. Positive psychology and tourism: a systematic literature review. TMS 14(3): 41-51.

HOSANY S \& GILBERT D. 2010. Measuring Tourists' Emotional Experiences toward Hedonic Holiday Destinations. J Travel Res 49(4): 513-526.

KIM J, RITCHIE J \& MCCORMICK B. 2012. Development of a scale to measure memorable tourism experiences. J Travel Res 51(1): 12-25.

KIRILLOVA K \& LEHTOX. 2015. An existential conceptualization of the vacation. Ann Tourism Res 55: 110-123.

LEE YC. 2013. The influence of personality traits health knowledge and product attributes on intent to purchase Taiwan's healthcare tourism products. Soc Behav Personal 41(3): 395-410.

LI C-Y \& TSAI B-K .2013. Impact of extraversion and sensation seeking on international tourism choices. Soc Behav Personal 41(2): 327-334.

MILANEZ B. 2015. Dialogues between social and natural sciences: contribution to the debate on socioenvironmental conflicts. An Acad Bras Cien 87: 2335-2348.

$\mathrm{OH} \mathrm{H}$, FIORE A \& JEOUNG M. 2007. Measuring experience economy concepts: Tourism applications. J Travel Res 46: 119-132.

PASSAFARO ET AL. 2015. The Sustainable tourist: Values, attitudes and personality. THR 15(4): 225-239.

PESTANA M \& GAJEIRO J. 2008. Análise de dados para ciências sociais: A complementaridade do SPSS, Lisboa : Edições Sílabo, 493 p.

PINTO C \& PAIS-RIBEIRO J. 2007. Construção de Uma Escala de Avaliação da Espiritualidade em Contextos de Saúde. Arq Med 21(2): 47-53.

PINTO C \& PAIS-RIBEIRO J. 2010. Avaliação da espiritualidade dos sobreviventes de cancro: implicações na qualidade de vida. Rev Port Sau Pub 28(1): 49-56.

SCORSOLINI-COMIN F, FONTAINE A, KOLLER S \& SANTOS M. 2013. From Authentic Happiness to Well-Being: The Flourishing of Positive Psychology. Psicol Refl Crít 26(4): 663-670.

SEABRA C, SILVA C, FAIAS C, ABRANTES I \& PAIVA O. 2014. Holistic tourism: A new form of living and feeling tourism. RTetD 21/22: 177-178. 
SELIGMAN M. 2013. Building the State of Wellbeing: A Strategy for South Australia. Adelaide Thinker in Residence 2012-2013, Adelaide: SA Department of the Premier and Cabinea, 9 p.

SIMKOVÁ E. 2014. Psychology and its application in tourism. Procedia - Social and Behavioral Sciences 114: 317-321.

SMITH M \& DIEKMANN A. 2017. Tourism and wellbeing. Ann Tourism Res 66: 1-13.

STROM T, LEMAIRE C, ZACNA J, MONTANEZ J \& BIRNBAUM B. 2018. Integration of Social Sciences and Humanities in Horizon 2020: Participants, Budget and Disciplines. $3^{\text {rd }}$ Monitoring report on SSH flagged projects funded in 2016 under the Societal Challenges and Industrial Leadership priorities, Luxembourg: Publications Office of the European Union, $6 \mathrm{p}$.

VITTERS $\varnothing$ J, VORKINN M, VISTAD OI \& VAAGLAND J. 2000. Tourist experiences and attractions. Ann Tourism Res 27(2): 432-450.

\section{How to cite}

GARCÊS S, POCINHO M \& JESUS SN. 2020. Psychometric analysis of the Tourism Wellbeing Scale (TWS): a multidisciplinary approach. An Acad Bras Cienc 92: e20190232. DOI 10.1590/0001-3765202020190232.

\section{Manuscript received on February 23, 2019; accepted}

for publication on September 22, 2019

\section{SORAIA GARCÊS ${ }^{1,2}$}

https://orcid.org/0000-0002-2970-9078

\section{MARGARINA POCINHO ${ }^{2,3}$}

https://orcid.org/0000-0002-9898-7143

\section{SAÚL N. DE JESUS ${ }^{2,4}$}

https://orcid.org/0000-0003-2019-1011

${ }^{1}$ Post-doctoral research fellow, Agência Regional para o Desenvolvimento de Investigação, Tecnologia e Inovação/ ARDITI, University of Madeira, Research Center for Regional and Local Studies (UMa-CIERL), Campus Universitário da Penteada, 9020-105 Funchal, Madeira, Portugal

${ }^{2}$ Researcher at the Research Centre for Spatial and Organizational Dynamics, Research Centre for Tourism, Sustainability and Well-being (CinTurs), University of Algarve, Faro, Portugal

${ }^{3}$ Associate Professor, General Council Member, University of Madeira, Campus Universitário da
Penteada, 9020-105, Funchal, Madeira, Portugal

${ }^{4}$ Vice-Rector, University of Algarve, Faculty of Human and Social Sciences, University of Algarve, Campus de Gambelas, 8005-139, Faro, Portugal

Correspondence to: Soraia Garcês

E-mail:soraiagarces@gmail.com

\section{Author contributions}

The authors contributed equally to the preparation and writing of the manuscript.

\section{(cc) BY}

